\title{
Comparison of Dry-Powder Inhaler and Pressurized Metered-Dose Inhaler Formulations of Extrafine Beclomethasone Dipropionate/Formoterol Fumarate/Glycopyrronium in Patients with COPD: The TRI-D Randomized Controlled Trial
}

This article was published in the following Dove Press journal: International Journal of Chronic Obstructive Pulmonary Disease

\author{
Kai-Michael Beeh' \\ Piotr Kuna ${ }^{2}$ \\ Massimo Corradi iD ${ }^{3}$ \\ Isabelle Viaud ${ }^{4}$ \\ Alessandro Guasconi $^{4}$ \\ George Georges (iD ${ }^{4}$ \\ 'Insaf Respiratory Research Institute, \\ Wiesbaden, Germany; ${ }^{2}$ Division of \\ Internal Medicine, Asthma and Allergy, \\ Barlicki University Hospital, Łódź, Poland; \\ ${ }^{3}$ Department of Medicine and Surgery, \\ University of Parma, Parma, Italy; ${ }^{4}$ Global \\ Clinical Development, Chiesi \\ Farmaceutici SpA, Parma, Italy
}

Background: Three 52-week studies in COPD have assessed the efficacy and safety of single-inhaler extrafine formulation triple therapy combining beclomethasone dipropionate (BDP), formoterol fumarate (FF) and glycopyrronium $(\mathrm{G})$ delivered via pressurized metereddose inhaler (pMDI). BDP/FF/G is now being developed for delivery via multi-dose drypowder inhaler (DPI; NEXThaler). This study aimed to demonstrate non-inferiority of BDP/ FF/G DPI vs pMDI for lung function.

Methods: Multicenter, randomized, double-blind, double-dummy, active-controlled, threeway cross-over study in patients with COPD and post-bronchodilator forced expiratory volume in 1 second $\left(\mathrm{FEV}_{1}\right)$ 30-80\% predicted. Patients received BDP/FF/G 100/6/10 $\mu \mathrm{g}$ via DPI and pMDI, and BDP/FF 100/6 $\mathrm{g}$ via pMDI, all two inhalations twice daily for four weeks, with treatments separated by two-week washout. The two co-primary objectives were to demonstrate non-inferiority between the two $\mathrm{BDP} / \mathrm{FF} / \mathrm{G}$ formulations for $\mathrm{FEV}_{1}$ area under the curve between 0 and 12 hours post-dose $\left(\mathrm{AUC}_{0-12 \mathrm{~h}}\right)$ normalized by time and trough $\mathrm{FEV}_{1}$ at 24 hours, both on Day 28. EudraCT 2017-004405-41.

Results: Of 449 patients screened, 366 were randomized, with 342 (93.4\%) completing all three treatment periods. The primary objectives were met, with changes from baseline in $\mathrm{FEV}_{1} \mathrm{AUC}_{0-12 \mathrm{~h}}$ and trough $\mathrm{FEV}_{1}$ on Day 28 similar for the two $\mathrm{BDP} / \mathrm{FF} / \mathrm{G}$ formulations, and the confidence intervals for the difference lying entirely within the pre-specified noninferiority criterion $(-50 \mathrm{~mL}):-20(-35,-6) \mathrm{mL}$ and $3(-15,20) \mathrm{mL}$ for $\mathrm{AUC}_{0-12 \mathrm{~h}}$ and trough $\mathrm{FEV}_{1}$, respectively. BDP/FF/G pMDI and DPI were statistically superior to BDP/FF for these endpoints $(\mathrm{p}<0.001)$. A similar proportion of patients experienced adverse events with each treatment $(15.5 \%, 18.7 \%$ and $15.4 \%$ with BDP/FF/G DPI and pMDI, and BDP/FF, respectively); the majority were mild or moderate, with few related to treatment.

Conclusion: Extrafine BDP/FF/G DPI and pMDI demonstrated similar efficacy and safety in patients with COPD, supporting the DPI formulation as a valid alternative.

Keywords: adrenergic beta- 2 receptor agonists, muscarinic antagonists, steroids, respiratory function tests, chronic obstructive pulmonary disease

\section{Background}

For patients with chronic obstructive pulmonary disease (COPD) who have exacerbations when receiving a long-acting $\beta_{2}$-agonist (LABA) plus a long-acting
Correspondence: Kai-Michael Beeh Insaf Respiratory Research Institute,

Wiesbaden, Germany

Tel +4961I 9854347

Email k.beeh@insaf-wi.de

International Journal of Chronic Obstructive Pulmonary Disease 2021:16 79-89 
muscarinic antagonist (LAMA), or symptoms or exacerbations when receiving an inhaled corticosteroid (ICS) plus a LABA, inhaled triple therapy with a triple combination of an ICS, a LABA and a LAMA is recommended. ${ }^{1}$

A single inhaler triple therapy is available that combines, in an extrafine formulation (ie, with mass median aerodynamic diameter $<2 \mu \mathrm{m}$ ), the ICS beclomethasone dipropionate (BDP), the LABA formoterol fumarate (FF) and the LAMA glycopyrronium $(\mathrm{G})$. Extrafine particles in aerosolized medicines are more able to consistently reach small airways than non-extrafine particles, ${ }^{2}$ enhancing delivery to these airways, a major site of airflow obstruction in $\mathrm{COPD},{ }^{3,4}$ with lower oropharyngeal deposition. ${ }^{5}$ Three prior 52 -week studies have assessed the efficacy and safety of this combination in patients with COPD. In the TRILOGY study BDP/FF/G reduced the rate of COPD exacerbations by $23 \%$ compared with $\mathrm{BDP} / \mathrm{FF}^{6}{ }^{6}$ in the TRINITY study BDP/FF/G reduced the rate by $20 \%$ compared with the LAMA tiotropium, ${ }^{7}$ and in the TRIBUTE study BDP/FF/G reduced the rate by $15 \%$ compared with the LABA/LAMA combination indacaterol/glycopyrronium. ${ }^{8}$ In all three studies, BDP/ $\mathrm{FF} / \mathrm{G}$ was delivered via pressurized metered-dose inhaler (pMDI); this formulation has been approved for the management of COPD in a number of countries, including throughout the European Union.

When selecting an inhaled therapy for a patient, it is important to not only consider the active molecules but also the patient's ability to use, and preference for, the device. ${ }^{1}$ Advantages of pMDIs include that they are: familiar to most patients (especially since the most common rescue medications are delivered via pMDI); they are compact; and instructions for use are consistent across products. However, their correct use requires hand actuation to be coordinated with inhalation, which can be difficult for some patients. In addition, although the pMDI remains the most common inhaler overall, ${ }^{9}$ dry-powder inhalers (DPIs) are the most commonly prescribed inhalers for maintenance therapy of asthma, COPD and asthmaCOPD overlap. ${ }^{10}$

The NEXThaler is a breath-activated, multi-dose DPI approved for the delivery of BDP/FF. The triple combination of $\mathrm{BDP} / \mathrm{FF} / \mathrm{G}$ is now being developed for delivery via this device to provide additional options for patients and physicians - for example, in patients who prefer a DPI or are unable to use a pMDI correctly. The NEXThaler can be used even by patients who can generate only a relatively low inspiratory force, ${ }^{11}$ its delivery performance is independent of inhalation flow rate, and it incorporates a dose counter, indicating the number of doses remaining and that counts down only following successful activation. Each inhaler contains sufficient drug to deliver a full month of therapy, eliminating the need to manually load individual capsules, and so removing one source of error with single-dose, capsule-based DPIs. ${ }^{12}$ Additional advantages of DPIs compared to other delivery mechanisms include the ability to achieve deep lung deposition, and that a spacer device is not required. ${ }^{12}$

The aim of the current study was to demonstrate the non-inferiority of the DPI vs pMDI formulations of extrafine $\mathrm{BDP} / \mathrm{FF} / \mathrm{G}$, in terms of lung function. Extrafine BDP/ FF (via pMDI) was included as a positive control to ensure assay sensitivity.

\section{Materials and Methods Trial Design and Participants}

This was a Phase II, multicenter, randomized, doubleblind, double-dummy, active-controlled, three-way crossover study. Eligible patients were $40-85$ years of age, diagnosed with COPD $\geq 12$ months prior to entry, postbronchodilator forced expiratory volume in 1 second $\left(\mathrm{FEV}_{1}\right) \quad 30-80 \%$ predicted, and had been receiving a stable regimen for $\geq 30$ days of LAMA monotherapy, ICS+LABA+LAMA, ICS+LABA, or LABA+LAMA (fixed or free combinations were acceptable). Main exclusion criteria were: a current diagnosis of asthma; a lower respiratory tract infection requiring antibiotics or a COPD exacerbation in the six weeks prior to screening; or clinically significant conditions that could have impacted the interpretation of the results. All patients provided written informed consent prior to any studyrelated procedure. Full inclusion and exclusion criteria are in the supplement.

Patients who met the inclusion and exclusion criteria entered a two-week open-label run-in period when they received BDP/FF 100/6 $\mu \mathrm{g}$, two inhalations twice daily (BID) via pMDI (Figure 1). At the end of the run-in period, patients were randomized to one of six treatment sequences using a balanced block randomization scheme generated by the interactive response technology provider. In each sequence, patients received three treatments, with each treatment taken for four weeks, and with treatment periods separated by two-week washout periods, when patients again received BDP/FF 100/6 $\mu \mathrm{g}$. The three study treatments were BDP/FF/G 100/6/10 $\mu \mathrm{g}$ via DPI, 


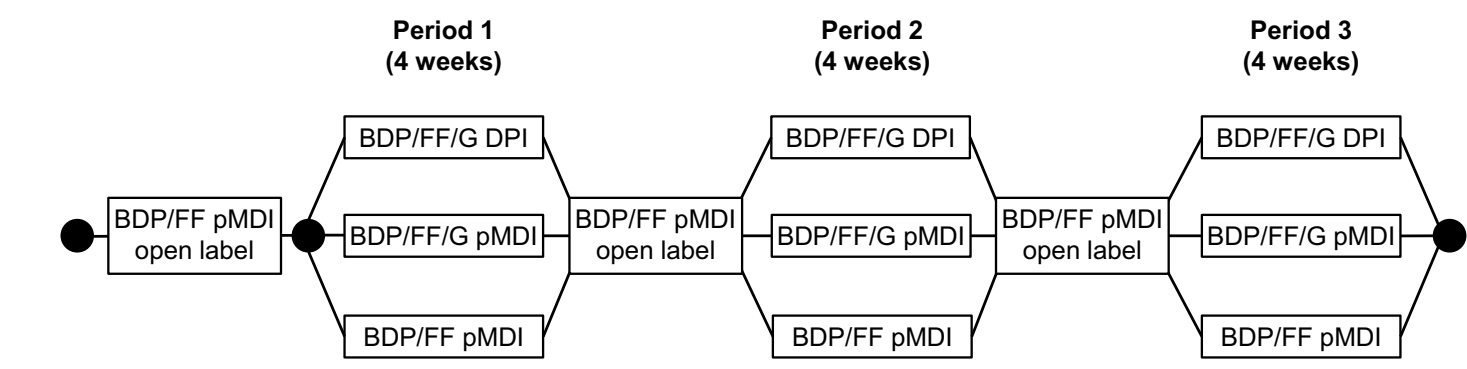

Screening Randomization

$\begin{array}{ccc}\begin{array}{c}\text { Run-in } \\ (2 \text { weeks) }\end{array} & \text { Wash-out } & \text { Wash-out } \\ \text { (2 weeks) } & \text { (2 weeks) }\end{array}$

Figure I Study design.

Abbreviations: BDP, beclomethasone dipropionate; FF, formoterol fumarate; PMDI, pressurized metered-dose inhaler; G, glycopyrronium; DPI, dry-powder inhaler.

$\mathrm{BDP} / \mathrm{FF} / \mathrm{G} 100 / 6 / 10 \mu \mathrm{g}$ via $\mathrm{pMDI}$, and BDP/FF 100/6 $\mu \mathrm{g}$ via pMDI, all two inhalations BID. The BDP/FF/G 100/6/ $10 \mu \mathrm{g}$ dose administered via DPI has previously been shown to provide similar deposition characteristics to the same dose administered via pMDI (Chiesi data on file). Patients, investigators, site staff, monitors and the sponsor's team were all blinded to treatment by the use of a double-dummy design.

Patients attended study visits on Days 1 and 28 of each period. Serial spirometry was assessed pre-dose and up to $12 \mathrm{~h}$ post-dose on Day 1 and up to $24 \mathrm{~h}$ post-dose on Day 28 of each treatment period, with data from the St. George's Respiratory Questionnaire (SGRQ) recorded pre-dose on both days. Patients were permitted salbutamol or terbutaline as rescue medication throughout the study (although not within $6 \mathrm{~h}$ prior to a visit), with use recorded on a diary card throughout the study.

The study was approved by the independent ethics committees at each institution, and was performed in accordance with the principles of the Declaration of Helsinki, and the International Conference on Harmonization notes for guidance on Good Clinical Practice (ICH/CPMP/135/95). There were no amendments to the protocol. The study is registered in EudraCT (2017-004405-41) and ClinicalTrials.gov (NCT03590379). This manuscript adheres to CONSORT guidelines.

\section{Outcomes}

The two co-primary objectives were to demonstrate noninferiority between the two $\mathrm{BDP} / \mathrm{FF} / \mathrm{G}$ formulations in terms of $\mathrm{FEV}_{1}$ area under the curve between 0 and 12 hours normalized by time $\left(\mathrm{AUC}_{0-12 \mathrm{~h}}\right)$ and trough
$\mathrm{FEV}_{1}$ at 24 hours, both on Day 28. FEV $\mathrm{AUC}_{0-12 \mathrm{~h}}$ measures the aggregate effect over the full dosing interval for a BID dosing regimen; trough $\mathrm{FEV}_{1}$ was selected to ensure that the LABA and LAMA components did not mask any potential differences in the ICS between the DPI and pMDI formulations. Superiority of BDP/FF/G pMDI vs $\mathrm{BDP} / \mathrm{FF}$ for $\mathrm{FEV}_{1} \mathrm{AUC}_{0-12 \mathrm{~h}}$ was also evaluated to demonstrate assay sensitivity.

Secondary endpoints were pre-dose morning $\mathrm{FEV}_{1}$ and $\mathrm{FEV}_{1} \mathrm{AUC}_{0-4 \mathrm{~h}}$ on Day 28, $\mathrm{FEV}_{1} \mathrm{AUC}_{0-12 \mathrm{~h}}$ on Day 1, peak $\mathrm{FEV}_{1}$ on Days 1 and 28 , the percentage of patients with a change from baseline in pre-dose morning $\mathrm{FEV}_{1}$ $\geq 100 \mathrm{~mL}$ on Day 28, SGRQ total and domain scores on Day 28 , and rescue medication use. In addition, safety and tolerability were evaluated.

\section{Sample Size and Statistical Methods}

Assuming 15\% would be non-evaluable, 354 patients were to be randomized for 301 patients to be included in the primary endpoint analyses. This would provide an overall study power of $85 \%$, with:

- approximately $92.5 \%$ power to detect non-inferiority in terms of $\mathrm{FEV}_{1} \mathrm{AUC}_{0-12 \mathrm{~h}}$ on Day 28, with a noninferiority margin of $-50 \mathrm{~mL}$, and assuming no difference between the two $\mathrm{BDP} / \mathrm{FF} / \mathrm{G}$ formulations, a within-subject standard deviation (SD) of $180 \mathrm{~mL}$ and a one-sided significance level of 0.025 ;

- approximately $100 \%$ power to detect superiority in terms of $\mathrm{FEV}_{1} \mathrm{AUC}_{0-12 \mathrm{~h}}$ on Day 28, assuming a mean difference of $100 \mathrm{~mL}$ between $\mathrm{BDP} / \mathrm{FF} / \mathrm{G}$ 
pMDI and BDP/FF pMDI, a within-subject SD of $180 \mathrm{~mL}$ and a two-sided significance level of 0.05 ;

- approximately $92.5 \%$ power to detect non-inferiority in terms of trough $\mathrm{FEV}_{1}$ on Day 28, with a noninferiority margin of $-50 \mathrm{~mL}$, and assuming no difference between the two $\mathrm{BDP} / \mathrm{FF} / \mathrm{G}$ treatments, a within-subject SD of $180 \mathrm{~mL}$ and a one-sided significance level of 0.025 .

The co-primary endpoints were evaluated in a hierarchical testing order: non-inferiority of $\mathrm{BDP} / \mathrm{FF} /$ $\mathrm{G}$ DPI vs pMDI for $\mathrm{FEV}_{1} \mathrm{AUC}_{0-12 \mathrm{~h}}$, then superiority of $\mathrm{BDP} / \mathrm{FF} / \mathrm{G}$ pMDI vs BDP/FF for $\mathrm{FEV}_{1} \mathrm{AUC}_{0-12 \mathrm{~h}}$, and finally non-inferiority of $\mathrm{BDP} / \mathrm{FF} / \mathrm{G}$ DPI vs $\mathrm{pMDI}$ for trough $\mathrm{FEV}_{1} . \mathrm{FEV}_{1} \mathrm{AUC}_{0-12 \mathrm{~h}}$ was calculated based on the actual times using the linear trapezoidal rule, with change from baseline analyzed using an analysis of covariance (ANCOVA) model with treatment, period and patient as fixed effects, and baseline $\mathrm{FEV}_{1}$ as a covariate. Non-inferiority of BDP/FF/G DPI vs pMDI was to be claimed if the two-sided 95\% CI of the adjusted mean difference between treatments lay entirely to the right of the pre-defined non-inferiority margin of $-50 \mathrm{~mL}$. Trough $\mathrm{FEV}_{1}$ on Day 28 was calculated as the mean of the two measurements at 23.5 hours and 24 hours post-dose, and was analyzed using the same ANCOVA model as for $\mathrm{FEV}_{1} \mathrm{AUC}_{0-12 \mathrm{~h}}$. A similar ANCOVA model was used for most of the secondary efficacy endpoints. $\mathrm{FEV}_{1}$ response (change from baseline $\geq 100 \mathrm{~mL}$ in pre-dose morning $\mathrm{FEV}_{1}$ ) was analyzed using a conditional logistic regression model with treatment and period as fixed effects, patient as strata and baseline $\mathrm{FEV}_{1}$ as covariate, and the rescue medication endpoints were analyzed using an analysis of variance model with treatment, period and patient as fixed effects.

The intention-to-treat (ITT) population was all randomized patients who received at least one dose of study medication and had at least one post-baseline efficacy evaluation available, and the per-protocol (PP) population was all patients in the ITT population with no major protocol deviations. The safety population was all randomized patients who received at least one dose of study medication. The non-inferiority comparisons between $\mathrm{BDP} / \mathrm{FF} / \mathrm{G}$ DPI and pMDI for the primary endpoints were conducted in both the ITT and PP populations; all other efficacy evaluations were conducted in the ITT population only. All safety evaluations were performed in the safety population.

\section{Results}

\section{Participants}

The study was conducted at 48 sites across six countries between 15 Jun 2018 and 6 Mar 2019. Of 449 patients screened, 366 were randomized, all of whom received at least one dose of study medication, with 342 (93.4\%) completing all three treatment periods. Reasons for non-

Table I Baseline Demographics and Disease Characteristics

\begin{tabular}{|c|c|}
\hline Parameters & $\begin{array}{l}\text { Overall } \\
N=366\end{array}$ \\
\hline Age (years) & $64.9(6.9)$ \\
\hline Gender, male, n (\%) & $215(58.7)$ \\
\hline Body mass index $\left(\mathrm{kg} / \mathrm{m}^{2}\right)$ & $27.6(5.7)$ \\
\hline Time since COPD diagnosis (years) & $9.5(6.5)$ \\
\hline \multicolumn{2}{|l|}{$\begin{array}{l}\text { COPD maintenance medication on study entry, } \\
n(\%)\end{array}$} \\
\hline ICS/LABA/LAMA & $127(34.7)$ \\
\hline ICS/LABA & $118(32.2)$ \\
\hline LABA/LAMA & $105(28.7)$ \\
\hline LAMA & $16(4.4)$ \\
\hline \multicolumn{2}{|l|}{ Smoking status, n (\%) } \\
\hline Ex-smoker & $|8|(49.5)$ \\
\hline Current smoker & $185(50.5)$ \\
\hline Smoking history, (pack-years) & $20.0(6.3)$ \\
\hline $\mathrm{FEV}_{\mathrm{I}}(\mathrm{L})^{*}$ & $1.440(0.478)$ \\
\hline $\mathrm{FEV}_{1} \%$ predicted $*$ & $51.4(12.2)$ \\
\hline $\mathrm{FEV}_{1} / \mathrm{FVC} *$ & $0.48(0.10)$ \\
\hline SGRQ total score ${ }^{\dagger}$ & $44.3(15.5)$ \\
\hline \multicolumn{2}{|l|}{$\begin{array}{l}\text { Number of COPD exacerbations in the } \\
\text { previous year, } n(\%)\end{array}$} \\
\hline 0 & $240(65.6)$ \\
\hline $\mathrm{I}$ & $113(30.9)$ \\
\hline$\geq 2$ & $13(3.6)$ \\
\hline
\end{tabular}

Notes: Data are mean (SD) unless specified otherwise; *Post-bronchodilator; ${ }^{\dagger} 356$ patients had data available.

Abbreviations: COPD, chronic obstructive pulmonary disease; ICS, inhaled corticosteroid; LABA, long-acting $\beta_{2}$-agonist; LAMA, long-acting muscarinic antagonist; $F E V_{1}$, forced expiratory volume in I second; FVC, forced vital capacity. 
A $\quad B D P / F F / G D P I \quad B D P / F F / G ~ p M D I \quad \square D P / F F ~ p M D I$

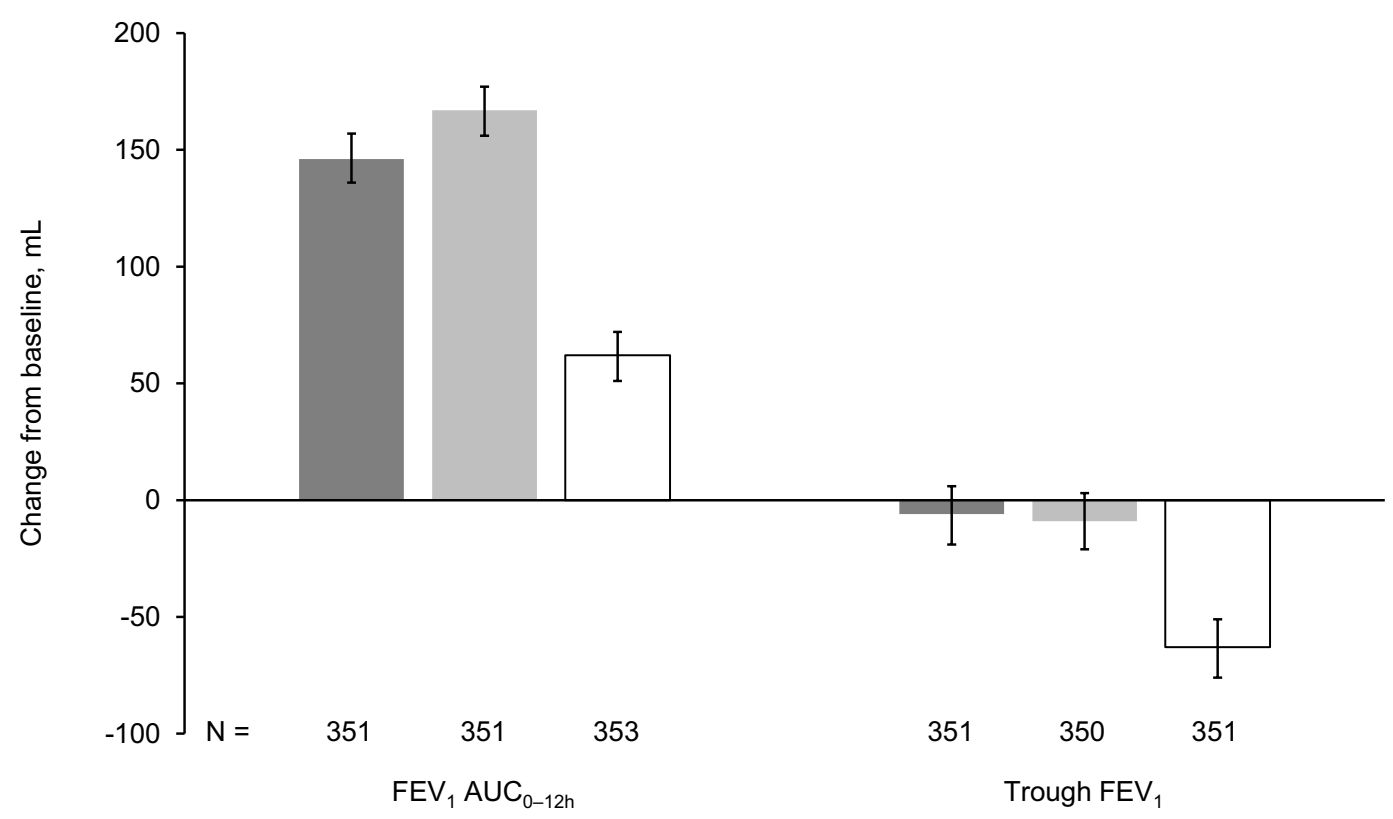

Endpoint

B Non-inferiority margin $(-50 \mathrm{~mL})$

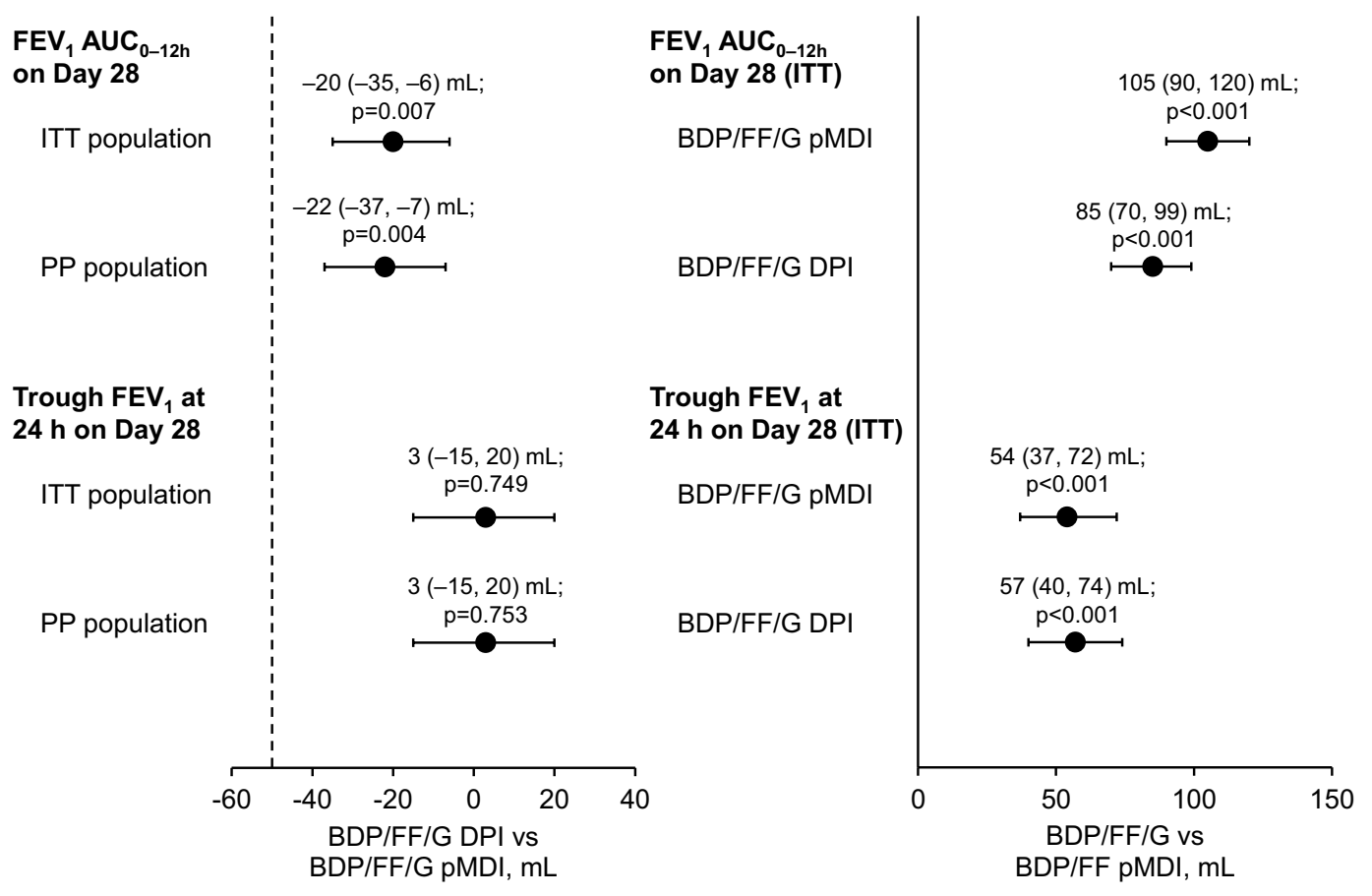

Figure $2 \mathrm{FEV}_{1} \mathrm{AUC}_{0-12 \mathrm{~h}}$ and trough $\mathrm{FEV}_{1}$ on Day 28 (co-primary endpoints): (A) Change from baseline (ITT population), and (B) treatment contrasts.

Notes: Bars in Panel (A) are adjusted mean changes from baseline and $95 \%$ confidence intervals; values in Panel (B) are adjusted mean treatment differences (95\% confidence intervals).

Abbreviations: $\mathrm{FEV}_{1}$, forced expiratory volume in I second; AUC, area under the curve; BDP, beclomethasone dipropionate; FF, formoterol fumarate; G, glycopyrronium; DPI, dry-powder inhaler; PMDI, pressurized metered-dose inhaler; ITT, intention to treat; PP, per protocol. 


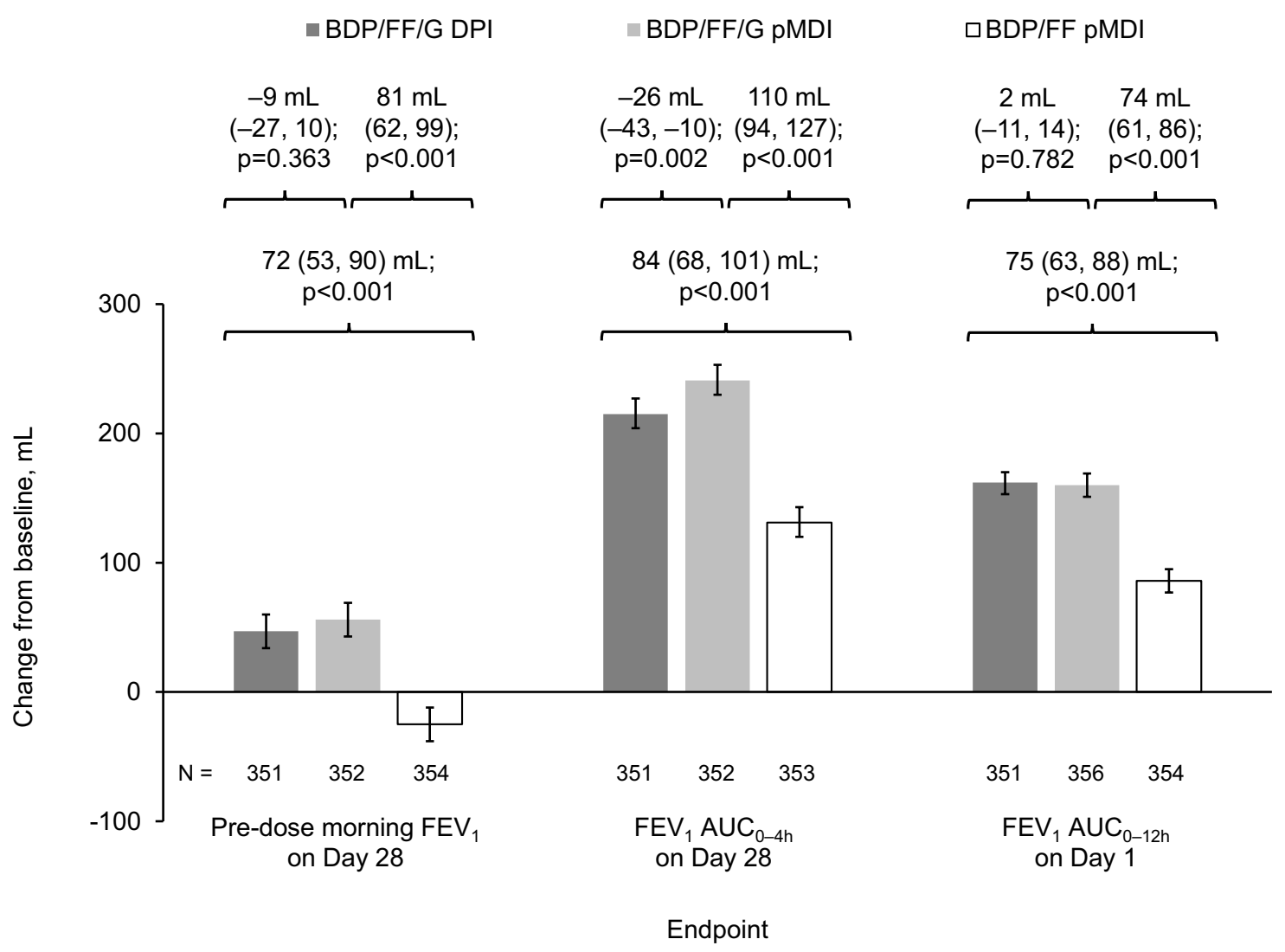

Figure 3 Pre-dose morning FEV 1 and $\mathrm{FEV}_{1} \mathrm{AUC}_{0-4 \mathrm{~h}}$ on Day 28, and $\mathrm{FEV}_{1} \mathrm{AUC}_{0-12 \mathrm{~h}}$ on Day I (ITT population).

Notes: Bars are adjusted mean changes from baseline and $95 \%$ confidence intervals; text is adjusted mean treatment differences ( $95 \%$ confidence intervals).

Abbreviations: $\mathrm{FEV}_{1}$, forced expiratory volume in I second; AUC, area under the curve; BDP, beclomethasone dipropionate; FF, formoterol fumarate; G, glycopyrronium; DPI, dry-powder inhaler; pMDI, pressurized metered-dose inhaler; ITT, intention to treat.

completion by the remaining 24 patients were withdrawal of consent (11 patients [3.0\%]), adverse events (7 [1.9\%]), loss to follow-up (1 [0.3\%]), death (1 [0.3\%]) and "other" (4 [1.1\%]). Baseline characteristics of the 366 randomized patients are shown in Table 1. These were similar between treatment sequences.

\section{Outcomes}

\section{Primary Endpoint}

The primary objectives were met. The changes from baseline in both $\mathrm{FEV}_{1} \mathrm{AUC}_{0-12 \mathrm{~h}}$ and trough $\mathrm{FEV}_{1}$ on Day 28 were similar with the two BDP/FF/G formulations (Figure $2 \mathrm{~A}$ ), with the confidence intervals for the differences between the DPI and pMDI formulations lying entirely to the right of $-50 \mathrm{~mL}$ (Figure $2 \mathrm{~B}$ ), meeting the prespecified criterion for non-inferiority, with consistent results in the ITT and PP analyses. Furthermore, BDP/ $\mathrm{FF} / \mathrm{G}$ pMDI and DPI were both statistically superior to $\mathrm{BDP} / \mathrm{FF}$ for these two endpoints, so demonstrating assay sensitivity.

\section{Secondary Endpoints}

Consistent with the primary endpoints, there was no relevant difference between the two BDP/FF/G formulations for pre-dose morning $\mathrm{FEV}_{1}$ or $\mathrm{FEV}_{1} \mathrm{AUC}_{0-4 \mathrm{~h}}$ on Day 28, $\mathrm{FEV}_{1} \mathrm{AUC}_{0-12 \mathrm{~h}}$ on Day 1, or peak $\mathrm{FEV}_{1}$ on Days 1 and 28 , with both formulations superior to $\mathrm{BDP} / \mathrm{FF}$ in all analyses (Figures 3 and 4). On Day 28, 128 (36.2\%), $125(35.0 \%)$ and $67(18.8 \%)$ patients receiving $\mathrm{BDP} / \mathrm{FF} /$ G DPI, BDP/FF/G pMDI and BDP/FF, respectively, were $\mathrm{FEV}_{1}$ responders (ie, $\geq 100 \mathrm{~mL}$ change from baseline in pre-dose morning $\mathrm{FEV}_{1}$ ). These equated to odds ratios of 1.03 (95\% CI $0.69,1.53 ; \mathrm{p}=0.890)$ for $\mathrm{BDP} / \mathrm{FF} / \mathrm{G}$ DPI vs pMDI, $3.13(2.00,4.88 ; \mathrm{p}<0.001)$ for $\mathrm{BDP} / \mathrm{FF} / \mathrm{G}$ pMDI vs $\mathrm{BDP} / \mathrm{FF}$, and $3.22(2.06,5.01 ; \mathrm{p}<0.001)$ for $\mathrm{BDP} / \mathrm{FF} / \mathrm{G}$ DPI vs BDP/FF.

The two BDP/FF/G formulations provided a similar decrease from baseline (ie, improvement) in SGRQ total score on Day 28, and both were superior to $\mathrm{BDP} / \mathrm{FF}$ (Figure 5). The greatest effect of $\mathrm{BDP} / \mathrm{FF} / \mathrm{G}$ was on the symptoms domain. The percentage of rescue-free days was 


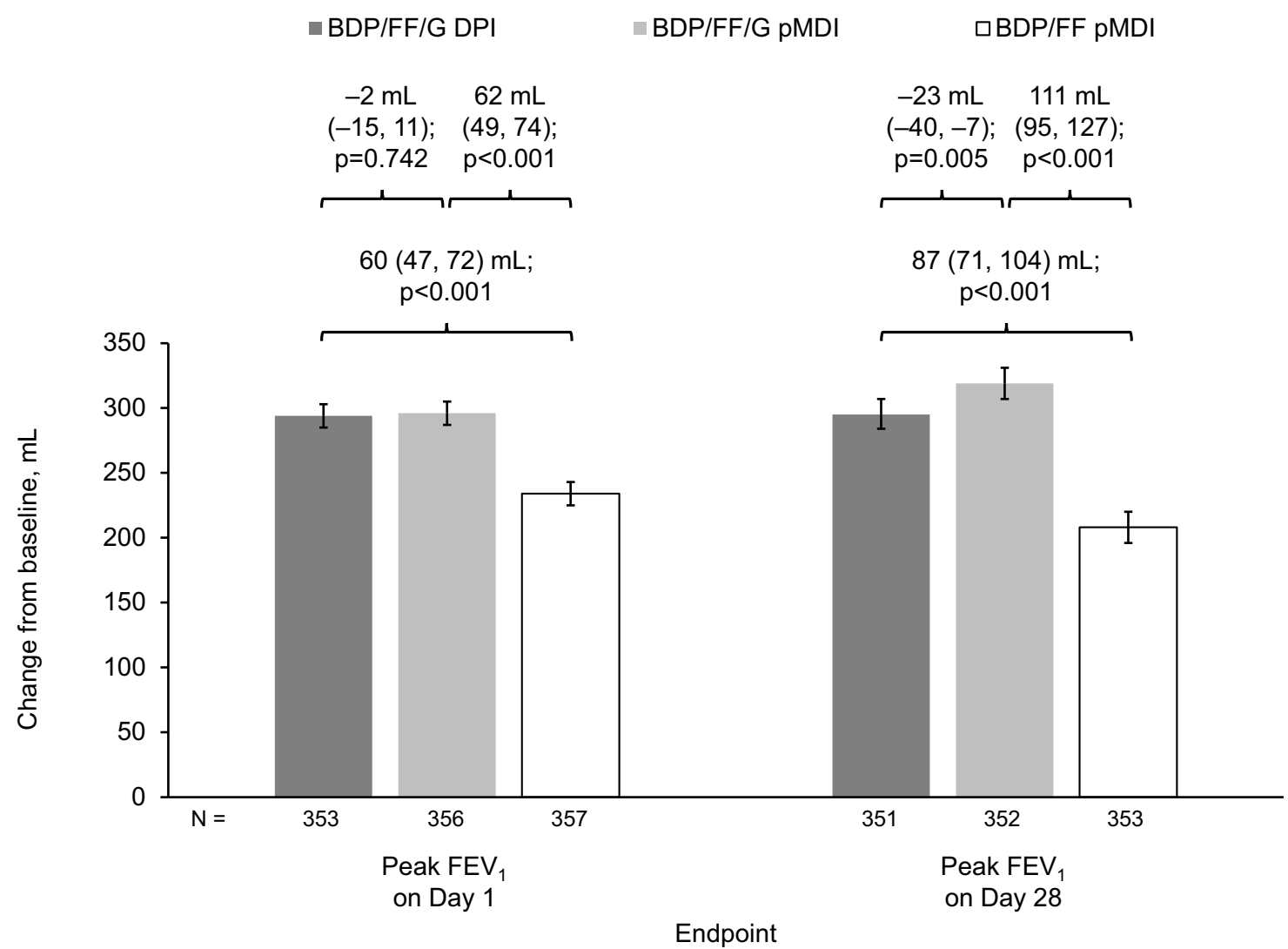

Figure 4 Peak FEV assessed up to $12 \mathrm{~h}$ post-dose on Days I and 28 (ITT population).

Notes: Bars are adjusted mean changes from baseline and $95 \%$ confidence intervals; text is adjusted mean treatment differences ( $95 \%$ confidence intervals).

Abbreviations: $\mathrm{FEV}_{1}$, forced expiratory volume in I second; BDP, beclomethasone dipropionate; FF, formoterol fumarate; G, glycopyrronium; DPI, dry-powder inhaler; PMDI, pressurized metered-dose inhaler; ITT, intention to treat.

high with all three treatments, and was similar with the two triple therapies; use of both triple therapies was associated with more rescue-free days than with $\mathrm{BDP} / \mathrm{FF}$ (Table 2). Consistent with the rescue-free days, the average puffs per day of rescue medication use was low in all three groups; use was similar with the two triple therapies, and was lower than with BDP/FF (Table 2).

\section{Safety}

A similar proportion of patients experienced adverse events with each treatment, both overall and for the most common preferred terms (Table 3 ). The majority of events were mild or moderate in severity, with few considered related to treatment. The only serious adverse events to occur in more than one patient with any treatment were pneumonia and COPD exacerbation, but no serious adverse events were related to treatment. Of the adverse events leading to treatment discontinuation, one was considered related to treatment - non-cardiac chest pain, during treatment with $\mathrm{BDP} / \mathrm{FF}$, that was non-serious but severe in intensity, and resolved without treatment. One patient died during the study due to a pulmonary hemorrhage; this was not considered related to treatment.

Overall, mean systolic and diastolic blood pressure and heart rate values were similar with all treatments, and changes from baseline were minimal. Changes from baseline in QTc (Fridericia's correction) interval were generally minimal and similar for all treatments, with a low proportion of patients reporting abnormal values or abnormal changes.

\section{Discussion}

The study met its co-primary endpoints, with the BDP/FF/ G pMDI and DPI formulations meeting the criterion for non-inferiority for both $\mathrm{FEV}_{1} \mathrm{AUC}_{0-12 \mathrm{~h}}$ and trough $\mathrm{FEV}_{1}$ on Day 28. In addition, both formulations were statistically superior to $\mathrm{BDP} / \mathrm{FF}$ for these endpoints supporting the sensitivity of the clinical study design and the endpoints used. Furthermore, there were no relevant differences between the two $\mathrm{BDP} / \mathrm{FF} / \mathrm{G}$ formulations across the 


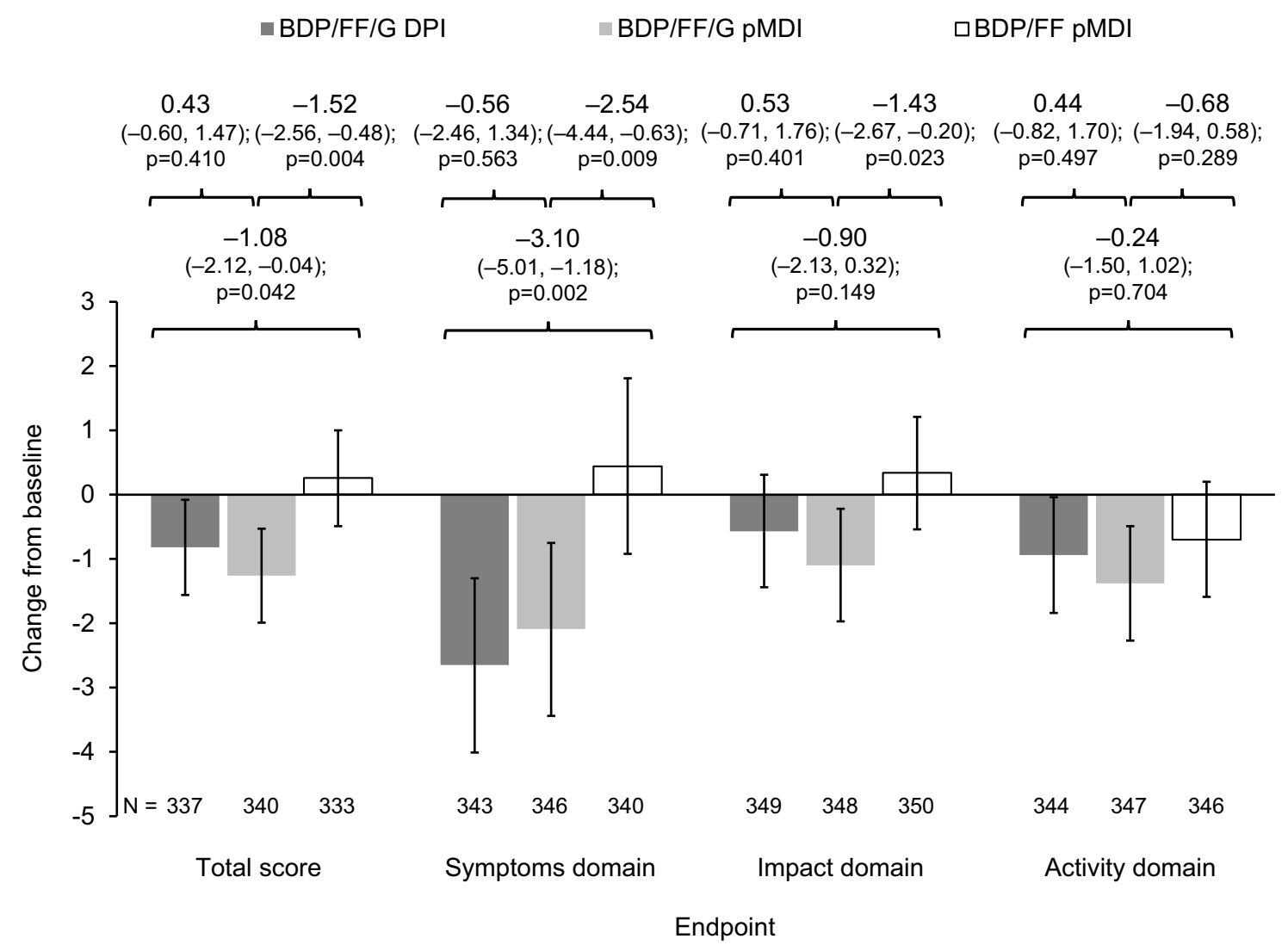

Figure 5 SGRQ total and domain scores on Day 28 (ITT population).

Notes: Bars are adjusted mean changes from baseline and $95 \%$ confidence intervals; text is adjusted mean treatment differences ( $95 \%$ confidence intervals). Abbreviations: $\mathrm{FEV}_{1}$, forced expiratory volume in I second; BDP, beclomethasone dipropionate; FF, formoterol fumarate; G, glycopyrronium; DPI, dry-powder inhaler; PMDI, pressurized metered-dose inhaler; ITT, intention to treat.

secondary lung function endpoints, and both were consistently statistically superior to $\mathrm{BDP} / \mathrm{FF}$, with odds ratios for the $\mathrm{FEV}_{1}$ responder analysis greater than 3 for the comparisons of both triple therapies to BDP/FF. There were similar trends for health status (as measured by SGRQ) and rescue medication use. Importantly, all three study treatments had similar safety profiles.
The 52-week TRILOGY study also evaluated the efficacy and safety of BDP/FF/G pMDI vs BDP/FF pMDI. TRILOGY recruited patients with post-bronchodilator $\mathrm{FEV}_{1}<50 \%$ and a history of at least one moderate or severe exacerbation, whereas the current study recruited a broader population of patients with $\mathrm{FEV}_{1} 30-80 \%$ and with no prior exacerbation requirement. Despite these

Table 2 Rescue Medication Use (ITT Population)

\begin{tabular}{|c|l|l|l|}
\hline & BDP/FF/G DPI (N=354) & BDP/FF/G pMDI (N=357) & BDP/FF pMDI (N=357) \\
\hline Rescue-free days, \% & $70.6(68.9,72.2)$ & $68.9(67.3,70.5)$ & $65.3(63.7,66.9)$ \\
\hline BDP/FF/G DPI vs BDP/FF/G pMDI & $1.64(-0.6 I, 3.89) ; p=0.154$ & & \\
\hline vs BDP/FF pMDI & $5.25(3.0 I, 7.49) ; p<0.001$ & $3.61(1.36,5.86) ; p=0.002$ & $0.902(0.836,0.968)$ \\
\hline Average use of rescue medication, puffs/day & $0.753(0.685,0.82$ I) & $0.736(0.668,0.803)$ & \\
\hline BDP/FF/G DPI vs BDP/FF/G pMDI & $0.017(-0.077,0.1 / 2) ; p=0.723$ & & \\
\hline vs BDP/FF pMDI & $-0.149(-0.243,-0.055) ; p=0.002$ & $-0.166(-0.261,-0.072) ; p<0.001$ & \\
\hline
\end{tabular}

Note: Data are adjusted mean or adjusted mean difference ( $95 \%$ confidence interval).

Abbreviations: BDP, beclomethasone dipropionate; FF, formoterol fumarate; G, glycopyrronium; DPI, dry-powder inhaler; pMDI, pressurized metered-dose inhaler. 
Table 3 Adverse Events, Overall and Most Common Preferred Terms ( $\geq 1 \%$ of Patients with Any Treatment for Adverse Events; $\geq 2$ Patients in Any Group for Drug-Related Adverse Events, Serious Adverse Events, and Severe Adverse Events)

\begin{tabular}{|c|c|c|c|}
\hline $\begin{array}{l}\text { Number of patients } \\
\text { (\%) }\end{array}$ & $\begin{array}{l}\text { BDP/FF/ } \\
\text { G DPI } \\
(\mathbf{N}=354)\end{array}$ & $\begin{array}{l}\text { BDP/FF/G } \\
\text { PMDI } \\
(\mathbf{N}=358)\end{array}$ & $\begin{array}{l}\text { BDP/FF } \\
\text { pMDI } \\
(\mathbf{N}=357)\end{array}$ \\
\hline Adverse events & $55(15.5)$ & 67 (18.7) & $55(15.4)$ \\
\hline COPD exacerbation & $12(3.4)$ & $13(3.6)$ & $7(2.0)$ \\
\hline Nasopharyngitis & $10(2.8)$ & $9(2.5)$ & II (3.I) \\
\hline Headache & $4(1.1)$ & $7(2.0)$ & $2(0.6)$ \\
\hline Back pain & 0 & $4(1.1)$ & $3(0.8)$ \\
\hline $\begin{array}{l}\text { Treatment-related } \\
\text { adverse events }\end{array}$ & $3(0.8)$ & $3(0.8)$ & $7(2.0)$ \\
\hline Dry mouth & $2(0.6)$ & 0 & $\mathrm{I}(0.3)$ \\
\hline Severe adverse events & $5(1.4)$ & $6(1.7)$ & $3(0.8)$ \\
\hline Pneumonia* & $\mathrm{I}(0.3)$ & $2(0.6)$ & 0 \\
\hline $\begin{array}{l}\text { Severe treatment-related } \\
\text { adverse events }\end{array}$ & 0 & 0 & I $(0.3)$ \\
\hline Serious adverse events & $4(1.1)$ & $6(1.7)$ & $\mathrm{I}(0.3)$ \\
\hline Pneumonia* & $\mathrm{I}(0.3)$ & $2(0.6)$ & 0 \\
\hline COPD exacerbation & 0 & $2(0.6)$ & I $(0.3)$ \\
\hline $\begin{array}{l}\text { Serious treatment-related } \\
\text { adverse events }\end{array}$ & 0 & 0 & 0 \\
\hline $\begin{array}{l}\text { Adverse events leading to } \\
\text { study treatment } \\
\text { discontinuation }\end{array}$ & I $(0.3)$ & $5(1.4)$ & I $(0.3)$ \\
\hline Pneumonia* & 0 & $2(0.6)$ & 0 \\
\hline $\begin{array}{l}\text { Adverse events leading to } \\
\text { death }\end{array}$ & 0 & $\mathrm{I}(0.3)$ & 0 \\
\hline
\end{tabular}

Notes: *Note that there was one pneumonia adverse event in one patient receiving BDP/FF/G DPI, which was considered severe in intensity and serious, but did not result in study discontinuation. Two patients receiving BDP/FF/G pMDI experienced one pneumonia adverse event each, both severe in intensity and serious, and resulted in study discontinuation.

Abbreviations: BDP, beclomethasone dipropionate; FF, formoterol fumarate; G, glycopyrronium; DPI, dry-powder inhaler; pMDI, pressurized metered-dose inhaler; COPD, chronic obstructive pulmonary disease.

differences, the results of the current study are consistent with those of TRILOGY, in which a significant improvement in pre-dose $\mathrm{FEV}_{1}$ and a higher proportion of $\mathrm{FEV}_{1}$ responders in the $\mathrm{BDP} / \mathrm{FF} / \mathrm{G}$ pMDI group was accompanied by a significantly greater improvement from baseline in SGRQ total score compared with the BDP/FF group. ${ }^{6}$ Furthermore, in TRILOGY the difference between BDP/
$\mathrm{FF} / \mathrm{G}$ pMDI vs BDP/FF for pre-dose $\mathrm{FEV}_{1}$ at Week 4 was similar in magnitude to the difference vs BDP/FF for both $\mathrm{BDP} / \mathrm{FF} / \mathrm{G}$ formulations in the current study, further supporting the consistency of effect. In addition to the requirement for a history of at least one exacerbation, the longer duration of follow-up in TRILOGY also meant that the occurrence of exacerbations could be evaluated - there was a significant $23 \%$ reduction in the rate of moderateto-severe exacerbations with BDP/FF/G pMDI compared with $\mathrm{BDP} / \mathrm{FF}$, together with a significant prolongation in the time to first moderate-to-severe exacerbation. Given improvements in lung function have been shown to correlate with reductions in exacerbation rate, ${ }^{13,14}$ it is likely that the similar improvements in lung function of the two $\mathrm{BDP} / \mathrm{FF} / \mathrm{G}$ formulations will result in similar effects on exacerbations. The safety results of the current study were also consistent with those of TRILOGY, in that the proportion of patients experiencing one or more adverse events was similar in the $\mathrm{BDP} / \mathrm{FF} / \mathrm{G}$ and $\mathrm{BDP} / \mathrm{FF}$ groups (although the overall incidence was much lower in the current study, given the different study design).

The Global Initiative for Chronic Obstructive Lung Disease report emphasizes the importance of tailoring the choice of inhaler device, with selection of the most appropriate device depending on a patient's ability and preference. ${ }^{1}$ This is particularly important since incorrect inhaler use is associated with reduced disease control in patients with COPD, ${ }^{15}$ and patient satisfaction with the inhaler device is associated with improved treatment compliance. ${ }^{16}$ In particular, in patients with COPD ease of use and dose recording were found to be important attributes of inhalers, and multi-dose inhalers were preferred to single-use refillable capsule-based devices. ${ }^{17}$ Importantly, no single device is suitable for all patients, and the availability of $\mathrm{BDP} / \mathrm{FF} / \mathrm{G}$ in two different inhalers will expand the choice available to patients and physicians, and should support patient preference, abilities and engagement in treatment decisions.

This study does have some limitations. First, it was designed around lung function endpoints; although SGRQ was included as an assessment of health status a four-week treatment period in a crossover design is not the most appropriate methodology for an endpoint that involves behavioral change. However, the consistency of these data with the results of the longer-term TRILOGY study suggests that the BDP/FF/ G DPI formulation is at least as effective as the pMDI formulation. In addition, a range of patients was recruited, with approximately a third each on triple therapy, ICS/LABA and 
non-ICS regimes. To address the potential impact of this on the study results, all patients received open-label BDP/FF pMDI for the two-week run-in and each wash-out period. In addition, due to the cross-over design, the impact of previous COPD therapies is considered marginal. Finally, symptoms were not formally evaluated; however, rescue medication use is an indirect assessment of symptoms, and the SGRQ symptoms domain results suggests that the BDP/FF/G DPI formulation is at least as effective on COPD symptoms as the pMDI - and that both formulations are more effective than BDP/FF pMDI.

\section{Conclusions}

The DPI and pMDI formulations of extrafine BDP/FF/G demonstrated similar efficacy and safety in patients with COPD, supporting the new DPI formulation as a valid option for both patients and physicians.

\section{Abbreviations}

ANCOVA, analysis of covariance; $\mathrm{AUC}_{0-12 \mathrm{~h}}$, area under the curve between 0 and 12 hours post-dose; BDP, beclomethasone dipropionate; COPD, chronic obstructive pulmonary disease; DPI, dry-powder inhaler; $\mathrm{FEV}_{1}$, forced expiratory volume in 1 second; FF, formoterol fumarate; FVC, forced vital capacity; G, glycopyrronium; ICS, inhaled corticosteroid; ITT, intention-to-treat; LABA, long-acting $\beta_{2}$-agonist; LAMA, long-acting muscarinic antagonist; pMDI, pressurized metered-dose inhaler; PP, per-protocol; SD, standard deviation; SGRQ, St. George's Respiratory Questionnaire.

\section{Data Sharing Statement}

Chiesi commits to sharing with qualified scientific and medical Researchers, conducting legitimate research, patient-level data, study-level data, the clinical protocol and the full clinical study report of Chiesi Farmaceutici S.p.A.-sponsored interventional clinical trials in patients for medicines and indications approved by the European Medicines Agency and/or the US Food and Drug Administration after 1st January 2015, following the approval of any received research proposal and the signature of a Data Sharing Agreement. Chiesi provides access to clinical trial information consistently with the principle of safeguarding commercially confidential information and patient privacy.

Other information on Chiesi's data sharing commitment, access and research request's approval process are available in the Clinical Trial Transparency section of http:// www.chiesi.com/en/research-and-development/, including the clinical trial data request portal.

\section{Ethics Approval and Informed Consent}

The study was approved by the independent ethics committees at each institution (see list in supplement). All patients provided written informed consent prior to any study-related procedure.

\section{Acknowledgments}

The authors would like to thank the investigators and patients at the investigative sites for their support of this study.

Writing support was provided by David Young of Young Medical Communications and Consulting Ltd. This support was funded by Chiesi Farmaceutici SpA.

Prior publication: The abstract of this paper was presented at the European Respiratory Society 2020 annual conference as a poster presentation. The abstract was published in the European Respiratory Journal (Beeh KM, Kuna P, Viaud I et al Eur Respir J 2020;56:3246. DOI: 10.1183/13993003.congress-2020.3246).

\section{Author Contributions}

All authors made a significant contribution to the work reported, whether that is in the conception, study design, execution, acquisition of data, analysis and interpretation, or in all these areas; took part in drafting, revising or critically reviewing the article; gave final approval of the version to be published; have agreed on the journal to which the article has been submitted; and agree to be accountable for all aspects of the work.

\section{Funding}

This study was funded by Chiesi Farmaceutici SpA. Employees of the sponsor were involved in study design, oversaw the conduct of the study, and (as authors) contributed to the development of the manuscript.

\section{Disclosure}

$\mathrm{KMB}$ is a full time employee of insaf Respiratory Research Institute. He has received personal or institutional compensations for services on advisory boards or consulting for AstraZeneca, Berlin Chemie, Boehringer, Chiesi, Elpen, GSK, Mundipharma, Novartis, Pohl Boskamp, Sanofi, sterna and Zentiva, and compensations for speaker activities in scientific meetings supported by AstraZeneca, Berlin Chemie, 
Boehringer, ERT, GSK, Novartis, Pfizer, Pohl Boskamp, Sanofi and Teva, all outside the submitted work. The institution has received compensations for design and performance of clinical trials from AstraZeneca, Boehringer, Chiesi, GSK, Novartis, Parexel, Pearl Therapeutics, sterna, and Zentiva. PK reports personal fees from Chiesi, Novartis, AstraZeneca, Boehringer Ingelheim, Berlin Chemie Menarini, Adamed, Polpharma and Lekam, all outside the submitted work and reports lectures for Novartis, GSK, Teva, AstraZeneca, Polpharma, and Lekam, outside the submitted work. MC received grants and honoraria for lectures from Chiesi Farmaceutici SpA, outside the submitted work. IV, AG and GG are employees of Chiesi Farmaceutici SpA, the sponsor of the study. The authors report no other potential conflicts of interest for this work.

\section{References}

1. Global Initiative for Chronic Obstructive Lung Disease. Global strategy for the diagnosis, management, and prevention of chronic obstructive pulmonary disease. Published 2021. Available from: https:// goldcopd.org/2021-gold-reports/. Accessed November 25, 2020.

2. Braido F, Scichilone N, Lavorini F, et al. Manifesto on small airway involvement and management in asthma and chronic obstructive pulmonary disease: an Interasma (Global Asthma Association - GAA) and World Allergy Organization (WAO) document. World Allergy Organ J. 2016;9(1):1-6. doi:10.1186/s40413-016-0123-2

3. Higham A, Quinn AM, Cançado JED, Singh D. The pathology of small airways disease in COPD: historical aspects and future directions. Respir Res. 2019;20(1):49. doi:10.1186/s12931-019-1017-y

4. Koo H-K, Vasilescu DM, Booth S, et al. Small airways disease in mild and moderate chronic obstructive pulmonary disease: a cross-sectional study. Lancet Respir Med. 2018;6(8):591-602. doi:10.1016/S22132600(18)30196-6

5. Usmani OS, Biddiscombe MF, Barnes PJ. Regional lung deposition and bronchodilator response as a function of beta2-agonist particle size. Am J Respir Crit Care Med. 2005;172(12):1497-1504. doi:10. 1164/rccm.200410-1414OC

6. Singh D, Papi A, Corradi M, et al. Single inhaler triple therapy versus inhaled corticosteroid plus long-acting $\beta 2$-agonist therapy for chronic obstructive pulmonary disease (TRILOGY): a double-blind, parallel group, randomised controlled trial. Lancet. 2016;388(10048):963-973. doi:10.1016/S0140-6736(16)31354-X
7. Vestbo J, Papi A, Corradi M, et al. Single inhaler extrafine triple therapy versus long-acting muscarinic antagonist therapy for chronic obstructive pulmonary disease (TRINITY): a double-blind, parallel group, randomised controlled trial. Lancet. 2017;389(10082):1919-1929. doi:10. 1016/S0140-6736(17)30188-5

8. Papi A, Vestbo J, Fabbri L, et al. Extrafine inhaled triple therapy versus dual bronchodilator therapy in chronic obstructive pulmonary disease (TRIBUTE): a double-blind, parallel group, randomised controlled trial. Lancet. 2018;391(10125):1076-1084. doi:10.1016/ S0140-6736(18)30206-X

9. Fink JB, Colice GL, Hodder R. Inhaler devices for patients with COPD. COPD J Chronic Obstr Pulm Dis. 2013;10(4):523-535. doi:10.3109/15412555.2012.761960

10. Ding B, Small M, Scheffel G, Holmgren U. Maintenance inhaler preference, attribute importance, and satisfaction in prescribing physicians and patients with asthma, COPD, or asthma-COPD overlap syndrome consulting for routine care. Int J Chron Obstruct Pulmon Dis. 2018;13:927-936. doi:10.2147/COPD.S154525

11. Corradi M, Chrystyn H, Cosio BG, et al. NEXThaler, an innovative dry powder inhaler delivering an extrafine fixed combination of beclometasone and formoterol to treat large and small airways in asthma. Expert Opin Drug Deliv. 2014;11(9):1497-1506. doi:10. 1517/17425247.2014.928282

12. Muralidharan P, Hayes D, Mansour HM. Dry powder inhalers in COPD, lung inflammation and pulmonary infections. Expert Opin Drug Deliv. 2015;12(6):947-962. doi:10.1517/17425247.2015. 977783

13. Jones PW, Donohue JF, Nedelman J, Pascoe S, Pinault G, Lassen C. Correlating changes in lung function with patient outcomes in chronic obstructive pulmonary disease: a pooled analysis. Respir Res. 2011;12:161. doi:10.1186/1465-9921-12-161

14. Zider AD, Wang X, Buhr RG, Sirichana W, Barjaktarevic IZ, Cooper CB. Reduced COPD exacerbation risk correlates with improved FEV1: a meta-regression analysis. Chest. 2017;152 (3):494-501. doi:10.1016/j.chest.2017.04.174

15. Melani AS, Bonavia M, Cilenti V, et al. Inhaler mishandling remains common in real life and is associated with reduced disease control. Respir Med. 2011;105(6):930-938. doi:10.1016/j.rmed.2011.01.005

16. Chrystyn H, Small M, Milligan G, Higgins V, Gil EG, Estruch J. Impact of patients' satisfaction with their inhalers on treatment compliance and health status in COPD. Respir Med. 2014;108 (2):358-365. doi:10.1016/j.rmed.2013.09.021

17. Molimard M, Colthorpe P. Inhaler devices for chronic obstructive pulmonary disease: insights from patients and healthcare practitioners. J Aerosol Med Pulm Drug Deliv. 2015;28(3):219-228. doi:10.1089/jamp.2014.1142

\section{Publish your work in this journal}

The International Journal of COPD is an international, peer-reviewed journal of therapeutics and pharmacology focusing on concise rapid reporting of clinical studies and reviews in COPD. Special focus is given to the pathophysiological processes underlying the disease, intervention programs, patient focused education, and self management protocols. This journal is indexed on PubMed Central, MedLine and CAS. The manuscript management system is completely online and includes a very quick and fair peer-review system, which is all easy to use. Visit http://www.dovepress.com/testimonials.php to read real quotes from published authors. 